\title{
Factors Predictive of Nonsentinel Lymph Node Involvement and Clinical Outcome in Melanoma Patients With Metastatic Sentinel Lymph Node
}

\footnotetext{
${ }^{1}$ Department of Oncological and Surgical Sciences, Surgery Branch, University of Padova, via Giustiniani 2, 35128, Padova, Italy ${ }^{2}$ Clinical Trial and Biostatistic Unit, Istituto Oncologico Veneto, IRCCS, Padova, Italy

${ }^{3}$ Department of Oncological and Surgical Sciences, Pathology Section, University of Padova, Padova, Italy
}

Erratum to: $10.1245 / \mathrm{s} 10434-007-9734-8$

Annals of Surgical Oncology

In the article entitled, "Factors predictive of nonsentinel lymph node involvement and clinical outcome in melanoma patients with metastatic sentinel lymph node," by Rossi et al (Ann Surg Oncol 2007 $10.1245 /$ s10434-007-9734-8) the first author's name of reference 16 was misspelled in the reference list and in Tables 5 and 6 .
The correct citation reads:

16. van Akkooi ACJ, de Witt JHW, Verhoef C, Schmitz PI, van Geel AN, Eggermont AM, Kliffen M. Clinical relevance of melanoma micrometastases $(<0,1 \mathrm{~mm})$ in sentinel nodes: are these nodes to be considered negative? Ann Oncol 2006; 17:1578-85.

Published online February 29, 2008.

The abstract of this manuscript was selected for oral presentation at the Society of Surgical Oncology (SSO) Annual Meeting (2007).

The online version of the original article can be found under doi: 10.1245/s10434-007-9734-8.

Address correspondence and reprint requests to: Carlo Riccardo Rossi, MD; E-mail: carlor.rossi@unipd.it

Published by Springer Science+Business Media, LLC @ 2008 The Society of Surgical Oncology, Inc. 